\title{
Writer Identity in Narrative and Argumentative Genres: A Case of Korean Students in the United States
}

\author{
Seongyong Lee \\ Graduate School of Education, State University of New York at Buffalo \\ 505 Baldy Hall, Buffalo, NY 14260-1000, USA \\ E-mail: seongyong@buffalo.edu
}

\author{
Received: 02-07-2016 \\ Accepted: 09-09-2016 \\ Advance Access Published: November 2016 \\ Published: 02-01-2017 \\ doi:10.7575/aiac.ijalel.v.6n.1p.178 \\ URL: http://dx.doi.org/10.7575/aiac.ijalel.v.6n.1p.178
}

\begin{abstract}
This study investigated how three Korean ESL students constructed their writer identity in narrative and argumentative genres of writing. For this purpose, the qualitative data collected from interviews, observations and written documents for eight weeks were analyzed according to a social constructionist perspective as a philosophical framework and Ivanič's approach to systemic functional linguistics as an analytic method. The results showed that the participants constructed a confident identity in narrative writing whereas they identified themselves with a less-confident writer in an argumentative genre. Accordingly, they adopted different strategies for the difficulties they were confronted with in two genres. In addition, while narrative essays showed their ownership of Korean culture as a sojourner in the U.S., argumentative essays revealed their ambivalent identity in an academic context. These findings shed light on the importance of a narrative writing task as a stepping stone for academic writing by empowering an L2 writer in terms of constructing an authoritative voice.
\end{abstract}

Keywords: L2 writing, writer identity, genre-based writing

\section{Introduction}

Although an increasing number of scholars in second language (L2) acquisition (SLA) have shown interest in the issue of an L2 learner's identity for the past twenty years, the significance of studying the process of an L2 writer's identity construction remains controversial among scholars (Helms-Park \& Stabapleton, 2003; Hyland, 2002; Ivanič \& Camps, 2001; Matsuda \& Tardy, 2007). Research on identity construction in L2 writing began to receive attention only in recent years when compared to other research areas in the discipline of L2 writing (Hyland, 2002). At this point, many scholars in the social sciences and SLA accept the idea that the construction of a learner's identity in social and/or cultural contexts is of great importance for the fulfillment of language learning (Erikson, 1974; Pierce, 1995; Norton, 2000). Therefore, there is still space for research on the process by which a learner's identity is constructed during L 2 composition.

The matter of constructing a writer's personal and/or professional identity in writing has been at the center of debate among many scholars (Helms-Park \& Stapleton, 2003; Hyland, 2002; Matsuda \& Tardy, 2007). Singhal (2004) reported that academic writing instruction is characterized by teaching the use of impersonal and formal words, passive voice, and objective writing conventions, all of which are focused on in academic writing courses in the United States (p. 11). However, Hyland (2002) cast doubt on the impersonal features of academic writing instruction in Western institutions. Referring to empirical studies, he argued that scholars in the humanities and social sciences tend to reveal their identity in their writing while writers in the science and engineering frequently hide their identity. This idea was supported by Matsuda and Tardy (2007) who argued that a writer's voice, part of a writer identity, plays an important role in interaction with the readers.

Until recent years, however, English as a second language (ESL) students' identity construction in narrative writing has been rarely addressed in L2 writing studies. In addition, comparative studies of narrative and academic writing in terms of the writer's identity are scarce in this discipline. To fill this gap, this study explored how a writer's identity was constructed in these two different genres of writing. I first analyzed how ESL students revealed their identity in narrative and argumentative writing assignments completed in American writing classes. I then considered the relevance of the writers' identity construction to the development of their writing. Placing due emphasis on the fact that these writers created their identity in a new culture, I looked closely at their self-perception in their narrative and argumentative texts. Finally, I examined their textual documents to determine how their ESL writer's identity was constructed and reflected in their writing. 


\section{Literature Review}

\subsection{Social Definition of Identity}

Scholars in identity studies have defined identity with reference to the relationship between an individual and society. While identity has been traditionally viewed as a distinct, stable, and single product made from an individual's perception of self, the social constructivists' view of identity is considered the aggregate of an individual's changing beliefs and perceptions, which are constructed in a social context (Gergen \& Davis, 1985; Ivanič, 1998; Tajfel, 1982; Turner, 1985; Turner \& Reynolds, 2010). Vygotsky (1978) saw identity as an emergent and dynamic state in an interaction with others. He assumed that the process of identity formation involves not an individual level of knowledge but the amounts, rather, to social achievement within a contextual discourse where social members share values and attitudes. This idea has played an important role in the emergence of social constructivism.

Identity is "not socially determined but socially constructed" (Ivanič, 1998, p. 12). In other words, the individual's identity is not stable or fixed; rather, it is fluid, flexible, and changeable according to various social contexts. Based on empirical research on writer identity, Ivanič (1998) argued that "how the self is implicated moment by moment" should be appreciated not only in terms of "power" but also in terms of "in power struggle" (p. 13). Struggle refers to an individual's resistance to the existing power in a society. Being involved in power struggle contributes to the social construction of an individual's identity. The link between language and social power has been explored in the study of ESL students' identity construction in a dominant language community where they may belong to a social minority group under the influence of power struggle in interaction with native speakers of English (Bok, 2012; Burke, 2010; Ivanič, 1998; Pierce, 1995; Weedon, 1997).

Drawing upon these theoretical considerations, the present study defines the process of identity construction as an emergent and dynamic state in a social context rather than a socially prescribed and predetermined self. While ESL students experience power struggle between them and a target language group, it is assumed that they negotiate the previously constructed identity to harmonize it with the newly emerging identity - identity is flexible and fluid in a given context (Cummings, 1996; Guerra, 2012). The "identity crisis" that they experience while challenging their existing one may contribute to the emergence of a new identity (Ivanič, 1998, p. 12). By scrutinizing ESL students' challenges and coping strategies, this study brings into a specific way in which this process is manifested in writing.

\subsection{Writer Identity in Academic Writing}

Based on the social constructivist perspective, Ivanič (1998) divided writer identity into four categories: autobiographical self, discoursal self, self as author, and social/institutional identity (pp. 23-31). While the first three categories represent the writers themselves working on a particular piece of writing, the last one is "abstract" and "prototypical" identity found in a sociocultural context (p. 27). The autobiographical self is related to a writer's sense of life history relevant to an act of writing. The discoursal self is based on the characteristics of the text as discourse and is associated with a writer's intended voice in the text. The self as an author is related to a writer's authoritativeness; it is also called an authoritative identity and is salient in academic writing. For Ivanič, all aspects of writer identity are emerging and changing over time as well as socially constructed. This study focuses on the discoursal self because this aspect is best analyzed based on the linguistic representation of writing and it is relevant to both narrative and argumentative writing (Ivanič, 1998).

The previous literature in the discipline of L2 writing suggested the need for research on a writer's voice as part of a writer's identity and for the instruction of ESL students with how to project it in writing (Burke, 2010; Cho, 2015; Hirvela \& Belcher, 2001; Ivanič \& Camps, 2001; Kang, 2004; Matsuda, 2001). L2 writers retain the capability to reveal their own writer's identity and voice constructed in L1 contexts, and so they should not be taught to conceal those individual traits in their academic writing (Hirvela \& Belcher, 2001; Matsuda, 2001). Although Western writing conventions sometimes encourage them to have an authoritative self, they are already familiar with this in L1 writing because constructing and projecting a writer's voice is common across cultures despite methodological variations (Matsuda, 2001). Thus, it is meaningful to instruct L2 writers to make their identity visible in an appropriate way in order to uplift the quality of their writing (Cho, 2015).

Some researchers argue that individual differences in constructing writer identities need to be respected in an academic writing classroom (Burke, 2010; Kang, 2004; Liu, 2008). L2 writers negotiate with and advance in academic writing when they strive to make their writer's identity an integral aspect of their work (Liu, 2008). In a longitudinal case study of six Korean international students' identity construction in L2 academic writing, Burke (2010) argued that research on writer identity helps understand L2 writers' individual characteristics in such a way that writing instructors can show them how to project their existing identity in a suitable way. Kang (2004) pointed out that assigning a narrative writing task in a writing course further allows a writing teacher to figure out an L2 writers' competence in English. Other research addressed the effect of identity style on language performance (Mohamadi \& Mokhtari, 2016) and the perception of self as an English learner in a context of an L2 digital literacy (Byfield, Shelby-Caffey, Bacon, \& Shen, 2016). Currently, however, there is a distinct lack of research that explores how a writer identity is differently constructed in a narrative genre of writing compared to an argumentative one.

To fill the gap in the previous literature, this study aims to explore how three Korean ESL students construct their writer's identity in narrative and argumentative writing from a comparative view. The following research questions guide this study. 
Research Question 1: How do three Korean ESL students perceive themselves as a writer while engaging in two different genres of writing?

Research Question 2: What strategies do they adopt in narrative and argumentative writing?

Research Question 3: How do they construct writer identity in two different genres of writing?

\section{Method}

A qualitative case study was used to understand three Korean ESL students' writer identity emerging in narrative and argumentative writing. A qualitative research method allows for access to their constructed identity since it is useful to figuring out the participants' deep voice (Glesne, 2011; Thomas, 2011).

\subsection{Research Site and Participants}

This research was conducted in a first-year composition classroom at a comprehensive university in America in 2014. As of fall 2014, the total number of enrollment was nearly 30,000 and 6,500 students were international. International students accounted for around $21.7 \%$, which made this university rank the top 20 U.S. universities in terms of the international student enrollment. This university was selected because every writing class included at least several international students due to a huge volume of international student enrollment. In a first-year writing class, international students interacted with an English native-speaking instructor and classmates, which provided an authentic ESL context for the participants.

Participants were three Korean freshmen-Jimin, Yuna, and Minho (pseudonyms)-who came from South Korea. I first met Jimin at school when I searched for participants among Korean international students at the research site and then she introduced Yuna and Minho to me as her friends. Jimin (female) was 20 years old, grown up and educated in Korea. Yuna (female) and Minho (male) were 19 years old and attended a high school in the Philippines for 2 years before they came to America. The participants were selected based on the similarities in their age, the length of stay in the U.S., and their English proficiency. They came to America in August 2013 and stayed in the U.S. for a year. Their TOEFL (iBT) scores ranged from 79 to 85 out of 120, showing that their overall English language proficiency was intermediate. Table 1 shows the participants' profile.

Table 1. The participants' profile

\begin{tabular}{|c|c|c|c|c|c|}
\hline Name & Gender & Age & Studied at & $\begin{array}{l}\text { TOEFL } \\
\text { (Writing) }\end{array}$ & $\begin{array}{l}\text { Length of Stay } \\
\text { in the U.S. (year) }\end{array}$ \\
\hline Jimin & Female & 20 & $\begin{array}{l}\text { South Korea } \\
\text { (Until coming to the } \\
\text { U.S.) }\end{array}$ & $\begin{array}{l}81 \\
(21)\end{array}$ & 1 \\
\hline Yuna & Female & 19 & $\begin{array}{l}\text { South Korea } \\
(\sim 16 \text { years old }) \\
\text { Philippines } \\
\text { (16 18 years old) }\end{array}$ & $\begin{array}{l}79 \\
(20)\end{array}$ & 1 \\
\hline Minho & Male & 19 & $\begin{array}{l}\text { South Korea } \\
(\sim 16 \text { years old }) \\
\text { Philippines } \\
\text { (16 18 years old })\end{array}$ & $\begin{array}{l}85 \\
(23)\end{array}$ & 1 \\
\hline
\end{tabular}

\subsection{Data Collection}

A qualitative research method of data collection was used in this study: four interviews and two written documents from each participant. The first-year composition class lasted fifteen weeks and the first eight weeks were selected for this study. After the first week's introduction, the second through the fourth week were dedicated to narrative writing and feedback. After a one-week interval, students engaged in argumentative writing for three weeks. Each task started with an introduction to genre-based writing and then proceeded to a first draft, feedback, and a final revision. They submitted their writing for feedback at the end of each task. The first draft without revision was collected in order to preserve their writer's identity in the text because the revised texts might have been affected by the instructor's feedback both in terms of writing convention and cultural factors. In narrative writing, students were asked to write about the most successful accomplishment or a moment of crisis in their life. The writing prompt in an argumentative task was "How technology has affected our lives?" or "How can a person make a business successful in a different culture?"

In addition, four interviews were conducted during the composition course both in and out of the classroom. Interviews were audio-recorded and then transcribed for the data analysis. The first interview was conducted at the first meeting in the classroom. It aimed at understanding the participants' life history as L2 learners. The second and third interviews were conducted to investigate the participants' perception of self as L2 writers in the U.S. and their sense of writer 
identity while composing narrative and argumentative essays. I collected two writing samples from the participants, analyzed them, and used them for the fourth interview, which aimed to confirm why they used specific linguistic forms in a certain context. Its main goal was to identify their discoursal self, which may have been revealed and constructed in writing (Ivanič, 1998). The Korean language was used as a means of communication for the interviews. Each interview lasted about 25 to 30 minutes for each person. All of the interviews were audio-recorded with a smart phone and then transcribed in Korean. The transcript in Korean was translated into English, which was used to clarify my interpretation in a follow-up interview with the participants.

Classroom observations were performed throughout the research period to understand how the participants behaved in interactions with their instructor and in response to writing tasks. I made up field-notes when I engaged in multiple observations in the classroom where I was positioned both as an insider and as an outsider. I used the observation data to confirm my interpretation of the interviews and analysis of the written texts.

\subsection{Data Analysis}

Two methods of data analysis were used to identify writer identity out of the interviews and their writing. Thematic analysis as a way of coding qualitative data was used to identify themes relevant to the process of the participants' writer identity construction (Glesne, 2011; Riessman, 2008). The transcribed interview data were open-coded to discover the thematic categories in terms of their properties and dimension. I conducted multiple reading of phrases, labeled the stories, and made a list of phrases as a code unit based on Corbin and Strauss (2007). Throughout the data analysis, I reviewed the data over and over again by comparing the coded categories. Those categories were crosschecked with the participants' responses in a follow-up interview and observations.

Analysis of the textual data was based on Ivanič's (1998) use of systemic functional linguistics to identify how a writer shows identity in a written document. I initially broke the documents into various parts by units of words, phrases, and sentences. Then, I searched for ideational meaning, which includes a writer's idea, content, subject-matter, and story. I also paid attention to interpersonal meaning, which refers to social identity by which one's choice of lexis and structures is under the influence of others' (Halliday, 1994).

\section{Results}

Analysis of three Korean ESL students' identity in narrative and argumentative writing is presented in accordance with research questions.

\subsection{RQ 1: Writer Identity from Interviews}

The two different genres of writing task helped three ESL writers to conceptualize their self in a separate way. They perceived themselves as an author to a greater extent in narrative writing than in argumentative writing. In particular, narrative writing task contributed to the development of their sense of ownership. Ivanič (1998) defines the self as an author to be a writer's autobiographical self. A writer's life-history may have an influence on his/her idea, a sense of self-worth, and their authorial presence.

Three Korean ESL students showed a confident writer identity when they engaged in a narrative writing task. It was reported that they felt more self-assured as an author when they engaged in a narrative task since its topic had the direct association with their life history. Jimin mentioned that familiarity with the topic gave her a sense of easiness:

I was more confident of myself in narrative writing because I didn't have to keep certain conventional style. I felt comfortable and honest to myself. So, I could think freely and logically. (Jimin)

However, in argumentative writing, they were concerned about how to deal with the unfamiliar topic, how to write an essay by following an academic writing convention, and what expressions to use. Thus, they became less confident of themselves as an author. Yuna felt a whit uncomfortable under the emotional pressure when involved in an argumentative task:

I am sure that I was confident of my writing [in narrative writing]. But it was not easy to write an argumentative essay because I had to keep the conventional rules. I was always not sure of whether I was writing it in a right way. So, I felt more nervous. (Yuna)

The more a writing task reflected their personal experiences in a given topic, the more confident the Korean writers were of their self. Jimin pointed out that the easiness of a narrative essay derived from an extensive chance to reflect her personal experiences in writing:

Narrative writing was easier for me than argumentative writing because I felt more comfortable when I could reveal my personal story. That's why I felt more confident of myself in that task. (Jimin)

According to my observation during Jimin's narrative writing, she looked relaxed in dealing with a topic. It did not take her long to write down key words in Korean on a piece of blank paper for brainstorming. Although she was sometimes cut off in mid-writing, she soon came back to writing without a long hesitation.

In sum, three Korean ESL students felt confident of their writing and self in narrative writing, whereas they were less confident in argumentative writing. The main factor was the degree of comfort and authoritativeness, which was subsequently based on the extent to which personal experiences were reflected in their writing. 
Although three Korean students had some difficulties in writing, they varied in two different genres. It was quoted that the difficulties in narrative writing were only related to linguistic aspects. In Jimin's case, the most challenging aspect of narrative writing was the use of appropriate words and phrases to express her thought and emotion. She felt dissatisfied with the expressions she chose to manifeste them:

In writing a narrative essay, I had difficulties in expressing myself. I didn't know what kind of words and phrases to use to express my emotion. I think this is because I am not good at English yet. It is so especially in the narration of my story. (Jimin)

Yuna approached the challenges in narrative writing in a deeper and more detailed way. She mentioned that she felt challenged in dealing with colloquial words to make up her own episode. She tried to use more colloquial expressions in narrative writing than in academic writing as she had learned it in the Philippines as a narrative writing style:

I thought I had to use more of colloquial words used by native speakers in their daily lives than I did in other types of writing... because this is what I learned about narrative writing in Philippines. However, I still felt limited in this. (Yuna)

However, Minho felt relatively comfortable to have access to the narrative writing style and its topic. This was because the topic was quite relevant to his life experiences and he did not need to follow a formal writing style:

In narrative writing I used simple words and sentences because there was no formal writing style. I tried to express my thoughts freely in narrative writing. (Minho)

On the other hand, the challenges they were confronted with in argumentative writing were mainly due to an unfamiliar topic and the academic writing convention. All participants shared a reflection that it was not easy to develop an idea based on a given topic and to write a paper according to an academic writing style. Jimin said that as the topic was not about her personal interests, an argumentative task made her less confident in her own ideas. She became blanked for a moment right when the topic was given:

It was not easy to think of a good idea about the topic. And it was also difficult to write an essay, sticking to a writing style of the [argumentative] writing. I had no idea what I had to write about when I was given the topic. (Jimin)

Yuna also confessed that she was always under psychological pressure with an argumentative task. She felt stressed when creating unique and influential idea to persuade the audience and to be praised by her professor:

I always have a heavy burden that I have to do well on my writing assignment because I was not sure of the quality of my writing. Especially in argumentative writing, the fact that I have to write logically always depresses me. (Yuna)

A classroom observation confirmed her interview. Yuna first hesitated to engage in writing. She looked perplexed and absent-minded while writing down something on a sheet of blank paper. She frequently adopted Korean for this stage and sometimes drew pictures to develop her idea about the topic.

The participants' behaviors in coping with the difficulties were also different in two genres. In narrative writing, Jimin used easy words to express her thoughts instead of looking up in a dictionary. For argumentative writing, on the contrary, she depended on other available sources, such as web-based dictionaries and her friends:

For a narrative I only thought of my experiences. I didn't look up in a dictionary. However, in an argumentative essay, I couldn't help depending on other sources like a web browser and my friends. So, it took me a longer time to complete the essay. (Jimin)

Yuna sometimes used key words in Korean and then translated them into English in argumentative writing whereas she directly wrote the sentences in English without this translation process in a narrative essay. She mentioned that he learned this strategy in the Philippines:

When I write an argumentative essay, I first write down some key words in Korean and then I think of the way to translate them into English effectively. But I don't do this for narrative writing. Because writing a personal journal was part of homework in the Philippines, I got kind of used to writing about my personal story (Yuna).

There is another difference in their attitude toward the usefulness of the two genres for the development of their writing skills. Ironically, although they felt more comfortable with a narrative genre, they shared an idea that an argumentative task was more helpful in improving their writing skills. Minho had a positive attitude toward the usefulness of an argumentative task for improving his writing ability:

I am not complaining that a writing class focuses mainly on academic writing because I think this task will prepare me for a job market. Writing an academic essay is difficult, but I believe it is helpful for my future. (Minho)

The challenges they faced were different in two genres of writing. Accordingly, their strategies to address those difficulties were also different. Narrative writing forced them to focus more on linguistic problems because the students were familiar with the topic whereas they focused both on language and on the topic in an argumentative task. Argumentative writing made them spend more time on subjectivization of the topic. In addition, they revealed different 
attitudes toward the two types of writing. They agreed that practicing an argumentative task is more beneficial to their writing skills than a narrative one.

\section{$4.3 R Q$ 3: Writer Identity in Narrative Writing}

Three ESL students' written documents provided more detailed information about the process in which their identity was formed in a written communication. Section three and four deal with how they projected and further negotiated their identity in a narrative and an argumentative writing tasks.

4.3.1 Negotiating identity as an owner of Korean culture while considering readers

Three Korean ESL writers considered the presence of readers even when they were writing about their personal life story. Minho wrote as if he was talking in front of his classmates at the first meeting. This shows that his writing was still based on a spoken modality in setting up a rapport with the readers even while engaging in composition. In order to establish a solid relationship with the readers, he attempted to show his own identity as a new-comer to an American society by explicitly showing where he came from. He negotiated his identity as an international student in the U.S. with an awareness of the prospective readers, whom he expected to understand his intention in his writing. For this he took account of how Korean culture, which he still belonged to, was different from American culture in terms of assigning family name to wife:

Hi. My name is Minho. I'm 19 years old and my country is South Korea..... Korea, the children follow father's way ... but mothers don't have to follow their husbands' way. For example, in USA when a couple got married, a wife change her family name to her husband's family name, but in Korea, we don't do like that. (Minho's writing)

In addition, Korean culture, his background, constructed Minho's identity as an owner of his own culture, which was well represented in the expository style of the following excerpt. Such an ownership that he had in Korean culture was salient, emphasized, and boasted in his writing as if he hoped to solidify his standing as a writer so that he would not be ignored by the audience in a dominant language culture. His desire to look knowledgeable about his own culture culminated in his falling into the hasty generalization fallacy about the relationship between a father and a son in Korea based on his personal experience. It is not true that all of the children follow the way their father does in terms of what religion they have. He wrote:

My mother's religion is Catholic but I have no religion because my father has no religion. In Korea, the children follow father's way. So my religion is same with my father's religion. (Minho's writing)

Such overstatement is not solely from his sense of ownership, but also comes from his discoursal interaction with the expected readers. I suggest that he intended to establish a solid stance as a member of Korean society and to further gain authority in taking account of a Korean-specific phenomenon in the presence of readers. This approach contributed to constructing his identity not only as an owner of Korean culture but also as an authoritative self in writing. Then, this writer identity, constructed in the communicative interaction with his professor and classmates, strengthened his sense of positioning as an L2 writer in the following part of a narrative essay. He mentioned:

Oh, yes. That's right... This part is not applicable to all types of father-son relationships. I just wanted to introduce Korean culture to my classmates and professor from different countries....and...I also wanted them to understand what are different from theirs. But like this way, I felt more confident in my writing. (Minho's interview)

Yuna also attempted to associate her writing with the response from the readers, the way of which was intertwined with the ownership of Korean culture. For her, Korean culture was viewed as scaffolding upon which she could reveal her own voice comfortably as Minho did. In the following excerpt, Yuna was communicating with the potential readers, showing humbleness as part of the Korean culture. Being humble, also called humiliation, is an important part of Asian culture under the influence of Confucianism. Yuna set up her stance as a member of a Korean society and at the same time she constructed her discoursal identity in a communicative context with her audience. By it is not my pride, she meant that she did not want to show off her school grade:

I ever had graded 38th in the whole school and my average was always higher than 90. It is not my pride. I just don't know why I should go to the Philippine. But my mother decided us to go abroad. (Yuna's writing)

She mentioned in a follow-up interview that she expected her readers to think that she did not boast her excellent grade since this way of writing might not have looked polite to the audience. She added that this politeness is of great importance among Koreans because an individual normally does not want to be conspicuous to others. On the other hand, she was not fully aware of the Western culture on the same issue, thereby revealing her identity as still belonging to the Korean way of expressing her personal achievement. Furthermore, such a writing style contributed to her emergent identity in a relationship with her readers from different cultures. Overall, her voice in this context gave way to her sense of authoritativeness in her writing.

\subsubsection{Identity as a sojourner in the U.S.}

What is salient in the following excerpt is Minho's systemic use of came and went, based on his perception of deictic reference in terms of the relativity of origin and destination. Although he lacked a native sensitivity to deictic expressions and meaning, he used a verb came for his movement to Seoul where he settled and stayed for a long time with his family. The connotation of this verb represents the final destination in the mind of a traveler rather than the 
origin. This deictic verb suggests that the writer still conceived an idea that Seoul was where he had to come back after all and that he put his mind in this place as his hometown although he was still in the United States at the very moment. Compared to this pragmatic verb, he used went in the other discoursal contexts on purpose. It is worth noticing that he knew how to use come and go in an appropriate context; that is to say, went was used in the places where he stayed temporarily as an alien:

I was born in Incheon and after that I came to Seoul right away.... when I was in 5th grade, I went to Australia for 2 months.... After one and half months I went to Sidney for 2 weeks... After that I went back to Korea ....After 2 months, I got a grade which I want and I went to USA. (Minho's writing)

Yuna conceived a plan that she would come back to her home country, Korea, for the future accomplishment. Although she tried her best to accommodate herself to a new society, her goal was still set upon her root culture. The use of subordinate conjunction If shows that she looked forward to what would happen in the future, not lingering in the past and present state. She also used be changed, meaning that the present situation where she belonged to a minority group was not an ideal one to her; rather, she hoped that the surroundings would be made different from her current status. In the subsequent phrases, such as would work in Korea and I am enviable, she directly revealed that she would come back to her origin, reversely suggesting that she stayed in the U.S. as an alien. Also, her desire to be an authentic member of American society was not identified in her writing:

If I'm telling about my future that can be changed, I would graduate at the business course and would work in Korea.... I am enviable for their pretty uniforms and the times with friends. (Yuna's writing)

\subsubsection{Transient and dynamic identity overcoming current challenges}

The following part of writing reveals Minho's transitional identity. It is noticeable that a grammatical tense changed from the past to the present, suggesting that his focus moved to the present situation. His life history until that time was headed for his becoming a university student in the U.S. While he always thought of his home city, Seoul, he was also aware of where he was and what he would have to do. An overall discourse in his narrative writing focused on how he came to America and became a student there:

In my academy there was a travel which go to Australia. I really want to join there so I asked to my mother and finally I got a permission ... After that I went back to Korea, and I began to study TOFEL to go to USA. After 2 months, I got a grade which I want and I went to USA. Now I am a student of OOO university. (Minho's writing)

Yuna opened her essay with a passive voice. She used was changed instead of changed, ergative voice which is often adopted by a native English speaker. It can be said that it is a common style found in Korean ESL students' writing; however, considering this phrase together with another part of her writing, it is suggested that she used this expression on purpose in order to show that her life had been under the influence of her parents. She went to the Philippines following her parents' decision without awareness of the reason behind it. Her life had been ascribed by the authority above; thus, she could not simply act against it. In the last sentence, she constructed an ambivalent identity between a daughter who listened to her mother well and an individual who pursued her own dream, guided by two words - Anyway and but:

My life was changed when my mother decided me to go and study in Philippines...... I just don't know why I should go to the Philippine. But... I...studied almost 2 years... Anyway I have something that makes me regret but now I am happy, thanks to my mother and would like to be well for my future. (Yuna's writing)

On the other hand, Jimin's essay is full of challenges in the U.S. and the process by which she had finally bounced back. Her identity in this context is quite liquid and dynamic in that she was in transit to an ideal identity. The process of overcoming these difficulties was possible with other's help, showing that she was dependent on a social network to address her current situation. The lexis frequently appearing in her essay are worried, adopt, not understand, difficult, all of which are associated with the challenges she had experienced in the U.S. Another group of lexis include help, could ask, kind and good, helped me, thankful, and consideration. These two groups of lexis, which are opposite to each other in their connotation, reveal that Jimin constructed a dynamic identity throughout her narrative essay:

I came to America 1 year 3 months ago with a Korean family... So at first, I was so worried about everything. However, I adapted to new circumstance because of others' help. (Jimin's writing)

Jimin initially sought help from a Korean family, where she stayed for the first few months, but the source of help gradually expanded into her friends, especially native-speakers of English. In other words, in the past, her identity only belonged to Korean culture but one and half years later she strived to become a member of an American society as well. Such an aspect of her gradual and temporal development shows that she had constructed an overcoming identity throughout her narrative writing.

Three Korean L2 writers kept active at constructing their identity while writing a narrative essay, not simply limited to showing their identity. Even though they were currently marginalized in their status as an international student in the U.S., their focus was always set upon their bright future. Such an attitude as a writer led to forming an emergent and dynamic identity, reflecting their hope to seek a better life after graduation. 
4.4 RQ 3: Writer Identity in Argumentative Writing

4.4.1 Identity as an author of academic essay

Although three Korean L2 writers were still incompetent in in an academic genre, they expressed expectations that their teacher and classmates would consider them to be professional and experienced in composition. Since they were aware of how their teacher would score their writing, they attempted to write an essay based on an academic writing style. One of the good examples is their employment of many connectors and adverbial phrases to link sentences. Jimin used so, and, because, and for example to show that she was dexterous at organization:

This is because the routine is busy and stressful in the competitive society...That's why the show TV program is breakthrough all over the ages....For example, the breadwinner feels great responsibility in managing many of his/her situations and problems in life....So, they cannot help getting stressed for their high education.....That's because it gives all student only one chance to take this exam a year...And most students in a university are usually suffering from pressure to be looking for a career. (Jimin's writing)

In a follow-up interview, she confirmed this interpretation:

I didn't know that I used too many conjunctions. Actually, I don't know much about conjunctions. I just thought it was the best way to write an essay in a more academic way. (Jimin's interview)

Yuna used and eight times in her essay, showing that she wanted the audience to view each sentence as being separate and logical. Instead of using diverse discoursing methods, such as connectors, referencing, and void, she heavily depended on the use of connectors as a way to show her ethos (Halliday, 1994). Not familiar with how to develop an idea in an organized way, she found them ideal to look experienced in her way of writing. Although many of them were either wrongly used or redundant, she used this strategy throughout her writing:

First of all, let's see the nearest technology around us, and maybe it will be the cell phone.... There were folder, slide or touch phone. And when the iphone was released, I thought it was very revolutionary. (Yuna's writing)

She confirmed this interpretation in an interview, stating that she wanted to stick to an academic writing convention by using appropriate conjunctions to connect sentences. She also confessed that this way was the best strategy for her to represent her writing as retaining a logical organization. However, she still did struggle to find the appropriate connectors in specific contexts.

4.4.2 Multiple voices - crossing the boundary between the two genres

Three Korean L2 writers kept crossing the boundary between the narrative and academic genres. First of all, they often used a person as a grammatical subject to start a sentence, which is generally regarded as inappropriate in an academic style. Hyland (2002) argues that an academic genre is characterized by a deliberate distance from one's subjective opinion, which may contribute to the objectiveness of the writing. Likewise, Yuna usually started a sentence with a nominal subject as learned in an academic writing class but a human subject sometimes appeared in other parts of her essay. A narrative style is identified in the following excerpt, showing that her identity was still ambivalent between a narrator and an academic writer although she learned how to write a good academic essay:

$I$ didn't see the phone like iphone or galaxy phone....It is not courtesy using phones on the eating table in Korea, but I see many times that people are touching their phones while eating. (Yuna's writing)

In the following excerpt, Jimin started the second paragraph by describing the representative members of Korean society. She adopted this approach to support her idea instead of citing information from outside resources, which is normally accepted in an academic writing convention. Here, she adopted the mixture of a descriptive and expository way to write about a Korean way of addressing stress. This feature suggests that she positioned herself in the middle of a narrative and an argumentative voice although she had been guided into how to write a good academic essay. She obtained an authoritative voice from narrative writing and applied it to an argumentative genre. By doing so, she presented herself as being a self in argumentative writing, which further helped her look authentic in this genre:

For example, the breadwinner feels a great responsibility in managing their situations and problems in their life.... So, they cannot help getting stressed for their high education. Then after high school, they have to study to enter prestigious universities or get a job which they wanted to work for. (Jimin's writing)

What needs to be pointed out in this excerpt is that Jimin's writer identity was indecisive about her status between the membership of Korean society and that of an academic community in the U.S. (see Ivanič, 1998). She described a normal life of Korean people under stress in a narrative way and used this episode as the evidence for her argument. She was still comfortable with accounting for some stories based on her own experience while she attempted to tuck this narrative story into an academic frame to which she adapted herself:

I thought I knew how normal Koreans live under the stress. And.... I thought this kind of experience can be evidence for my opinion. But I now think that I should have added a topic sentence at the front of the paragraph in academic writing. (Jimin's interview)

\subsubsection{Identity as an L2 writer}

Argumentative essays showed three Korean ESL students' identity as L2 writers in a systematic way. The perspective of traditional SLA might view some of the language use in their writing as belonging to interlanguage, which has some degree of distance from a native model. Even aside from the discussion of the ownership of English either by a native 
speaker or by a non-native one, some expressions are that of Koreans', not of Americans'. One of these examples is Jimin's employment of a few relative clauses although they might be redundant:

Then after high school, they have to study to enter prestigious universities or get a job which they wanted to work for. Especially there is a big event, which is examination for all of the students to evaluate their performance and then they apply to certain university according to their grades. (Jimin's writing)

She tried to use English grammar in an appropriate and professional way, still matching academic convention in English, but in some part she failed to attain this goal. She also used the direct translation from Korean into English, which made the whole sentence sound unnatural to a native-speaking reader. These patterns set her in a status of an L2 writer, whose writing was imperfect and less skillful to the eyes of her instructor and classmates. She confirmed this interpretation in a follow-up interview:

Well, I tried to use relative clauses to show that my writing is good. But...that part (relative clauses) was pointed out by my professor as an 'incorrect usage.' (Jimin's interview)

Yuna used definite article the to refer to certain noun in her writing. Even though she knew the usage of this article to some extent, she made a mistake in applying her explicit knowledge to a specific context:

And soon after, the Samsung launched the galaxy phone, and other companies did too. (Yuna's writing)

In a follow-up interview, she confirmed that she knew how to use a definite article but she could not come up with the right way to use it in a sentence:

I learned in Philippines that I have to use the to point out some noun previously mentioned. But whenever I try to write something, I forget almost everything. That's my problem. (Yuna's interview)

While writing an argumentative essay, Yuna constructed an L2 writer identity, who has explicit knowledge about the use of language, namely grammar, but does not transform this knowledge into implicit one. This writer has difficulties in applying knowledge previously obtained in a grammar class to the practical use of it in writing.

\section{Discussion}

This study explored three Korean ESL students' construction of writer identity in narrative and argumentative writing by analyzing data from interviews, observations, and written texts. First, they constructed different identities in the two genres because there were differences in the way they perceived their self as a writer. In argumentative writing, they showed their less confident identity as L2 writers, still feeling confused in addressing the topic and adapting to academic writing conventions. This result corroborates Hyland's (2002) finding that ESL writers in Hong Kong felt difficulties in constructing a confident identity in academic writing because they were trained not to use first person pronouns. In narrative writing, however, they showed confidence and authoritativeness in their writing because the topic was pertinent to their personal story. They also took a relaxed attitude toward the topic and the content of the writing, which further reinforced their confident writer identity. This result suggests that narrative writing allow them to feel more willing to reflect their own voice in a written text and thus help them to construct an authoritative voice in their own text.

Second, a writing teacher needs to apply different approaches to teaching narrative and academic genres of writing. In this study, three ESL students adopted different strategies in two genres since they were confronted with distinct difficulties. While they had only linguistic difficulties in narrative writing, they experienced troubles in the use of language, in addressing the topic, and in developing appropriate details in an argumentative task. To deal with such difficulties they used alternative words and phrases to express their emotions in narrative writing whereas they relied on many outside sources in an argumentative essay, including electronic or online dictionaries and their friends. This result may be associated with the different ways they constructed a writer identity in these two genres. Their heavy dependence on their own lexicon in narrative writing was due to their sense of ownership of the story. In comparison, their search for outside sources in an argumentative genre can be interpreted as the reflection of their distance from an authoritative voice. Thus, as Martin (1997) argued in research on a genre-based writing instruction, ESL students can gain benefits from the multiple ranges of writing activities based on different genres.

Third, a narrative writing activity needs to be included in an ESL writing curriculum because it helps ESL students to be equipped with an authoritative voice in writing. The analysis of textual data in this study revealed that while the narrative essays showed their authoritative identity with an ownership of Korean culture in the U.S., the argumentative genre revealed their mixed stance between an L2 writer and an academic writer in an academic community. In narrative writing, they were successful at revealing aspects of their identity not only as an authentic writer but also as a Korean student. In comparison, in argumentative writing, they wanted to look more professional but they inevitably showed their L2 writer identity as unexperienced and limited in their use of the English language. Burke (2010) argued that Korean culture contributed to her 6 Korean ESL writers' hesitation to show an authoritative voice in an academic genre. In comparison, Ko (2010) held that narrative writing opens a possibility that "an expressive and creative power", which then provides them with a sense of authoritativeness. Therefore, narrative writing can be used as a stepping stone leading to an academic genre, which requires a writer to keep an authoritative voice (Hirvela \& Belcher, 2001; Liu, 2008; Matsuda, 2001). 


\section{Conclusion}

The findings in this study have some pedagogical implications for L2 writing instruction and research. First, both narrative and argumentative tasks allow L2 writers to construct an authoritative voice in L2 composition. Matsuda (2001) argued that projecting an authoritative voice in L2 writing is of great significance in that it contributes to establishing writers' own repertoire where the writer develops their own idea in academic writing. In this study, three Korean L2 writers were successful in revealing their voice in narrative writing. In this vein, a narrative genre of writing can serve as a stepping stone for academic writing. Thus, I suggest that a composition curriculum needs to include a narrative writing task because its value has been neglected in most of the composition courses in Western culture (Singhal, 2004).

Second, teaching students to construct writer identity in both narrative and argumentative essays helps develop their communicative skills in interaction with an audience. While engaging in composition, they recognize the presence of readers, which then may lead to establishing a communicative discourse where they can secure their own voice. Ivanič and Camps (2001) argue that an L2 writer's discoursal identity develops when the writer evaluates the values and the knowledge of the readers. In the present study, L2 writers were actively involved in setting up an interactional identity in an attempt to fulfill the expectations of the readers in terms of academic writing conventions. This will further help them to be versed in how to communicate with the members of a dominant language community effectively based on their own voice (Ivanič, 1998; Matsuda, 2001).

Third, engaging in a narrative writing task can be a channel through which L2 writers can ease the emotional distress they experience as members of a minority group in the United States. Polkinghorne (1991) suggested that stories give writers a chance to conceptualize their personal identity by reflecting their true self in writing. Such a conceptualization process allows them to be more confident about themselves. Others have also reported that instructional narrative writing helps writers to secure their mental health (Danoff-Burg, Mosher, Seawell, \& Agee, 2010). Danoff-Burg et al. (2010) stated that traumatic memories can be alleviated through sharing stories because patients can simplify their terrible memories, which are not restored "as sensory perceptions, obsessional ruminations, or behavioral reenactments, as in the case of posttraumatic stress disorder" (p. 342). Such a discussion in previous research sheds light on the importance of a narrative writing task for L2 writers who may be marginalized in a target language community (Burke, 2010).

Finally, research on the construction of writer identity may contribute to teacher training in a composition course. Understanding writer identity is particularly crucial in L2 writing instruction because L2 writers may integrate cultural and even personal elements into their writing based on their authoritative voice (Cho, 2015; Matsuda, 2001). Writing instructors may misconstrue L2 writers' intentions in using specific expressions and styles if they decontextualize the students' texts. On the other hand, trained to identify students' writer identity, teachers can understand what is behind their linguistic choices so that they can subsequently guide them into what is expected in a specific genre of writing.

This study has a couple of limitations. Because this study employed only three participants, the findings cannot be generalized extensively. In addition, since the duration of the current research was only two months, a longitudinal approach is needed to achieve more conclusive results.

\section{Acknowledgements}

I would like to express my gratitude to Dr. Hohsung Choe from Hankuk University of Foreign Studies for his inspiring comments.

\section{References}

Bok, E. (2012). English language learner's literacy and identity work in online spaces. Modern English Education, 13(2), 17-35.

Burke, S. B. (2010). The construction of writer identity in the academic writing of Korean ESL students: A qualitative study of six Korean students in the U.S. (Unpublished doctoral dissertation). Indiana University of Pennsylvania, Pennsylvania, USA.

Byfield, L., Shelby-Caffey, C., Bacon, H., \& Shen, X. (2016). Digital literacy and identity formation in 21st century classrooms: Implications for second language development. International Journal of Applied Linguistics and English Literature, 5(1), 39-45. Retrieved from http:/www.journals.aiac.org.au/index.php/IJALEL/article/view/1959/1770

Cho, H. (2015). A corpus-assisted investigation on the quality-dependent differences in writer visibility in L2 writing. Modern English Education, 16(4), 1-22.

Corbin, J., \& Strauss, A. (2007). Basics of qualitative research: Techniques and procedures for developing grounded theory (3rd ed.). London: Sage Publications.

Cummings, J. (1996). Negotiating identities: Education for empowerment in a diverse society. Ontario, CA: California Association for Bilingual Education.

Danoff-Burg, S., Mosher, C. E., Seawell, A. H., \& Agee, J. D. (2010). Does narrative writing instruction enhance the benefits of expressive writing? Anxiety, Stress \& Coping, 23(3). 314-352. doi:10.1080/10615800903191137 
Erikson, E. H. (1974). Youth and crisis, (Repr. ed.). London: Faber and Faber.

Gergen, K., \& Davis, K. (Eds.) (1985). The social construction of the person. New York: Springers.

Glesne, C. (2011). Becoming qualitative researchers (4th ed.). New York: Longman.

Guerra, L. (2012). Learners' identity construction in the context of English as an international language. International Journal of Applied Linguistics and English Literature, 1(7), 117-126.

Retrieved from http://www.journals.aiac.org.au/index.php/IJALEL/article/view/816/748

Halliday, M. A. K. (1994). An introduction to functional grammar (2nd ed.). London: Edward Arnold.

Helms-Park, R., \& Stapleton, P. (2003). Questioning the importance of individualized voice in undergraduate L2 argumentative writing: an empirical study with pedagogical implications. Journal of Second Language Writing. 12(3), 245-265. http://dx.doi.org/10.1016/j.jslw.2003.08.001

Hirvela, A., \& Belcher, D. (2001). Coming back to voice: The multiple voices and identities of mature multilingual writers. Journal of Second Language Writing, 10, 83-106. http://dx.doi.org/10.1016/S1060-3743(00)00038-2

Hyland, K. (2002). Authority and invisibility: Authorial identity in academic writing. Journal of Pragmatics. 34, 10911112. doi:10.1016/S0378-2166(02)00035-8

Ivanič, R. (1998). Writing and identity: The discoursal construction of identity in academic writing. Philadelphia: John Benjamins.

Ivanič, R., Camps, D. (2001). I am how I sound: Voice as a self-representation in L2 writing. Journal of Second Language Writing, 10(1), 3-33. http://dx.doi.org/10.1016/S1060-3743(01)00034-0

Kang, J. Y. (2005). Written narratives as an index of L2 competence in Korean EFL learners. Journal of Second Language Writing, 14, 259-279. http://dx.doi.org/10.1016/j.jslw.2005.10.002

Ko, B. (2010). Two ESL Korean children's narrative writing in relation to genre-based approach. English Teaching, 65(4), 103-129.

Liu, Y. (2008). Taiwanese students' negotiations with academic writing: Becoming "playwrights and film directors". Journal of Second Language Writing, 17, 86-101. http://dx.doi.org/10.1016/j.jslw.2007.10.003

Martin, J. R. (1997). Analysing Genre: Functional Parameters. In F. Christie \& J. R. Martin (Eds.). Genre and Institutions: Social Processes in the Workplace and School. (pp. 3-39). London: Cassell.

Matsuda, P. K. (2001). Voice in Japanese written discourse: Implications for second language writing. Journal of Second Language Writing, 10(1-2), 35-53. http://dx.doi.org/10.1016/S1060-3743(00)00036-9

Matsuda, P. K., \& Tardy, C. M. (2007). Voice in academic writing: The rhetorical construction of author identity in blind manuscript review. English for Specific Purposes, 26(2), 235- 249. http://dx.doi.org/10.1016/j.esp.2006.10.001

Mohamadi, Z., \& Haji Mokhtari, F. (2016). Identity styles: Predictors of reading and writing abilities. International Journal of Applied Linguistics and English Literature, 5(5), 102-108. Retrieved from http://www.journals.aiac.org.au/index.php/IJALEL/article/view/2495/2174

Norton, B. (2000). Identity and language learning: Gender, ethnicity, and educational change. Harlow, England: Longman/Pearson.

Pierce, B. N. (1995). Social identity, investment, and language learning. TESOL Quarterly, 29(1), 9-31. DOI: $10.2307 / 3587803$

Polkinghorne, D. E. (1991). Narrative and self-concept. Journal of Narrative and Life History, 1(2\&3). 135-153.

Riessman, C. K. (2008). Narrative methods for the human sciences. Thousand Oaks, CA: Sage.

Singhal, M. (2004). Academic writing and generation 1.5: Pedagogical goals and instructional issues in the college composition classroom. The Reading Matrix, 4(3). 1-13.

Tajfel, H. (Ed.) (1982). Social identity and intergroup relations. Cambridge: Cambridge University Press.

Thomas, G. (2011). How to do your case study: A guide for students and researchers. London: Sage Publications.

Turner, J. C. (1985). Social categorization and self-concept: A social-cognitive theory of group behavior. In E. J. Lawler (Ed.). Advances in group processes: Studies in the social psychology of intergroup relations (Vol. 2, pp. 77-122). London: Academic Press.

Turner, J. C., \& Reynolds, K. J. (2010). The story of social identity. In T. Postmes \& N. Branscombe (Eds.). (pp. 13-32). Abindon, UK: Psychology Press.

Vygostky, L. S. (1978). Mind in society. Cambridge: Harvard University Press. 